\title{
A FORMAÇÃO CONTINUADA DE PROFESSORES: CONSIDERAÇÕES ACERCA DOS SABERES E DA PRÁTICA REFLEXIVA
}

\author{
THE CONTINUED TEACHER TRAINING: CONSIDERATIONS ABOUT \\ KNOWLEDGE AND REFLECTIVE PRACTICE
}

Angela Hess Gumieiro ${ }^{1}$

\begin{abstract}
RESUMO: Este artigo tem como objetivo discutir a formação continuada de professores, evidenciando o que determina a legislação nacional sobre algumas prerrogativas, assim como destacar algumas considerações acerca dos saberes e da prática reflexiva dos professores em meio à formação continuada. Para a realização do estudo foi utilizada a pesquisa de natureza bibliográfico-documental. O corpus de análise compõe-se dos seguintes documentos: LDB, Lei 9.394/96, o Decreto n ${ }^{\circ}$ 8.752/16, o PNE (2014-2024), a Resolução n $^{\text { }} 2$, de 1 de julho de 2015. Foram consultadas diferentes fontes, a saber: García (1995), Candau (1996), Nóvoa (1992; 1995), Gatti (2008), Pérez Gómez (2001), entre outros. Concluímos ressaltando a importância do aumento de estudos que busquem as especificidades nas ações de formação continuada levando em conta os saberes e as práticas dos professores, sendo que temos na legislação os direitos à formação continuada dos professores.
\end{abstract}

Palavras-chave: Formação continuada. Professores. Saberes e prática reflexiva.

ABSTRACT: This article aims to discuss the continuing education of teachers, evidencing what determines the national legislation on some prerogatives, as well as to highlight some considerations about the know led geand reflective practice of teachers in the mids to continuing education. For the accomplishment of the study was used the research of nature bibliographicdocumentary. The corpus of analysis consists of the following documents: LDB, Law $\mathrm{n}^{\circ}$ 9.394/96, Decree $n^{\circ}$. 6.755/09, PNE (2014-2024), Resolution $n^{\circ} .2$ of July 1, 2015. Different sources were consulted, to know, Garcia (1995), Candau (1996), Nóvoa (1992, 1995), Gatti (2008), Pérez Gómez (2001), among others. We conclude by emphasizing the importance of increasing studies that seek the specificities of continuing education actions takingin to account the knowledge and practices of teachers, and we have in the legislation the rights to continuing education of teachers.

Keywords: Continuing education. Teachers. Knowledge and reflective practice.

\section{INTRODUÇÃO}

O campo de discussão sobre formação continuada teve maior intensidade a partir da década 1990, em que tivemos a elevação do nível educacional da população e a democratização,

\footnotetext{
${ }^{1}$ Mestre em Educação pela Universidade Federal da Grande Dourados (UFGD). E-mail: angelahessufgd@gmail.com
} 
dessa forma a profissão docente foi colocada no foco nas políticas implementadas e na pesquisa educacional.

Apreender os conceitos atribuídos a formação continuada de professores torna-se de fundamental importância, pois, "é com base nos conceitos subjacentes aos termos que as decisões são tomadas e as ações são propostas, justificadas e realizadas" (MARIN, 1995, p.13).

Marin (1995) ao estudar a terminologia da formação continuada mostra que a opção por determinado termo não restringe apenas à escolha de nomes para identificar ações formativas. E sim revela dada concepção formativa com explícitas opções teórico-metodológicas, que trazem implicações no processo da formação, embora essas concepções muitas vezes não estejam claras para aqueles que planejam, executam, avaliam e àqueles que participam de ações de formação continuada.

Aceitamos também as contribuições de García (1995), que concebe a formação continuada como sendo o conjunto de atividades desenvolvidas pelos professores em exercício com objetivo formativo, realizadas individualmente ou em grupo, visando tanto ao desenvolvimento pessoal como ao profissional, na direção de prepará-los para a realização de suas atuais tarefas ou outras novas que se coloquem.

Lembramos, ainda, as palavras de Alarcão (1998, p. 100), ao conceber a formação continuada "como o processo dinâmico por meio do qual, ao longo do tempo, um profissional vai adequando sua formação às exigências de sua atividade profissional”. Sendo assim,

[...] a formação continuada visa ao desenvolvimento das potencialidades profissionais de cada um, a que não é alheio o desenvolvimento de si próprio como pessoa. Ocorrendo na continuidade da formação inicial, deve desenrola-se em estreita ligação com o desempenho da prática educativa (ALARCÃO, 1998, p. 106).

Lima (2001) ressalta que a formação continuada é a articulação entre o trabalho docente, o conhecimento e o desenvolvimento profissional docente, tendo uma postura reflexiva diante da prática. Menciona que a formação continuada pode estar "a serviço da reflexão e da produção de um conhecimento sistematizado, que possa oferecer a fundamentação teórica necessária para a articulação com a prática criativa do professor em relação ao aluno, à escola e à sociedade" (LIMA, 2001, p. 32).

A autora Gatti (2008), apresenta as seguintes considerações sobre a formação continuada:

[...] ora se restringe aos limites de cursos estruturados e formalizados oferecidos após a graduação, ou após ingresso no exercício do magistério, ora é tomado de modo amplo e genérico, como compreendendo qualquer tipo de atividade que venha a contribuir para o desempenho profissional - horas de 
trabalho coletivo na escola, reuniões pedagógicas, trocas cotidianas com os pares, participação na gestão escolar, congressos, seminários, cursos de diversas naturezas e formatos, oferecidos pelas Secretarias de Educação ou outras instituições para pessoal em exercício nos sistemas de ensino, relações profissionais virtuais, processos diversos, enfim tudo que possa oferecer ocasião de informação, reflexão, discussão e trocas que favoreçam o aprimoramento profissional, em qualquer de seus ângulos, em qualquer situação (GATTI, 2008, p. 57).

Diante disso, acreditamos que a formação continuada pode ser considerada um processo no desenvolvimento profissional, favorecendo as trocas entre os docentes, mediante processos de reflexão e análise crítica em colaboração com os pares.

O texto está organizado da seguinte maneira: na seção 1 apresentamos os apontamentos da legislação sobre a Formação Continuada de professores; na seção 2 analisamos as considerações acerca da formação continuada, dos saberes e da prática reflexiva dos professores e posteriormente as considerações finais.

\section{A formação continuada de professores: o que diz a legislação}

Nesta seção nos propomos evidenciar o que determina a legislação nacional sobre algumas prerrogativas que objetivam impulsionar a elaboração e a realização de propostas de formação continuada.

No Brasil, a formação continuada teve suas ações impulsionadas, a partir da década de 1990, a educação e a formação docente adquiriram valor estratégico nas reformas educacionais. Na Lei de Diretrizes e Bases da Educação n 9.394, de 20 de dezembro de 1996 (BRASIL, 1996), a formação continuada tem por finalidade assegurar aos profissionais da educação o aperfeiçoamento da profissão por meio da intervenção institucional pública (municipal ou estadual), assim:

Art. 87 (das disposições transitórias) - Cada município e supletivamente, o Estado e a União, deverá:

Parágrafo III- realizar programas de capacitação para todos os professores em exercício, utilizando, também para isso, os recursos da educação a distância (BRASIL, 1996).

Foi também nessa década que começa a ser instituído um quadro legal referente à formação continuada dos professores, a LDB/96 no título VI, postula o direito à formação continuada a todos os profissionais do ensino da educação básica e ainda aponta fundamentos e responsabilidades dessa formação no país, mas sem definir princípios e procedimentos para a sua realização,

Art. 61 - A formação dos profissionais da educação, de modo a atender às especificidades do exercício de suas atividades, bem como aos objetivos das diferentes etapas e modalidades da educação básica, terá como fundamentos: 
I - a presença de sólida formação básica, que propicie o conhecimento dos fundamentos científicos e sociais de suas competências de trabalho;

II - a associação entre teorias e práticas, mediante estágios supervisionados e capacitação em serviço;

III - $\mathrm{o}$ aproveitamento da formação e experiências anteriores, em instituições de ensino e em outras atividades (BRASIL, 1996).

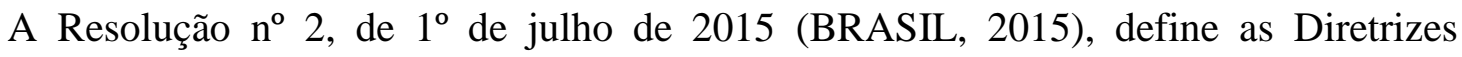
Curriculares Nacionais para a formação inicial em nível superior e para a formação continuada, no Capítulo VI, trata especificamente sobre a formação continuada dos profissionais do magistério:

Art. 16. A formação continuada compreende dimensões coletivas, organizacionais e profissionais, bem como o repensar do processo pedagógico, dos saberes e valores, e envolve atividades de extensão, grupos de estudos, reuniões pedagógicas, cursos, programas e ações para além da formação mínima exigida ao exercício do magistério na educação básica, tendo como principal finalidade a reflexão sobre a prática educacional e a busca de aperfeiçoamento técnico, pedagógico, ético e político do profissional docente (BRASIL, 2015).

O Plano Nacional de Educação (PNE) 2014-2024, focalizado nas Metas 15 e 16, aborda a questão da formação inicial e continuada de professores. Segundo Azevedo; Magalhães (2015, p. 22), o texto apresenta um discurso que opta por modelos de formação docente que "valorize[m] a experiência prática", como expresso na estratégia 15.3, retomando a lógica de valorização dos "saberes da experiência" em detrimento de conhecimentos da área de atuação profissional. O processo de formação continuada presente mais largamente nas Metas 15 e 16 encontram-se organizadas na primeira em 13 estratégias, buscando:

Garantir, em regime de colaboração entre a União, os Estados, o Distrito Federal e os Municípios, no prazo de 1 ano de vigência deste PNE, política nacional de formação dos profissionais da educação de que tratam os incisos I, II e III do caput do art. 61 da Lei ${ }^{\circ}$ 9.394, de 20 de dezembro de 1996, assegurado que todos os professores e as professoras da educação básica possuam formação específica de nível superior, obtida em curso de licenciatura na área de conhecimento em que atuam (BRASIL, 2014).

A estratégia 16.1 do PNE (BRASIL, 2014), por exemplo, prevê o dimensionamento da demanda por formação continuada em regime de colaboração (Federal, Estadual e Municipal), mas não apresenta sobre as formas e outros detalhes de como ocorrerá a formação continuada.

De acordo com as autoras Azevedo e Magalhães (2015, p. 23), ressaltam que "juntas, essas Metas propõem diversas ações, legislando sobre os modelos de formação inicial e 
continuada, a valorização da carreira do magistério, o processo de mercantilização da formação para o trabalho docente".

O Decreto $\mathrm{n}^{\mathbf{0}}$ 6.755, de 29 de janeiro de 2009, que institui a Política Nacional de Formação de Profissionais do Magistério da Educação Básica foi revogado pelo Decreto $\mathrm{n}^{\circ}$ 8.752, de 9 de maio de 2016, que institui a Política Nacional de Formação dos Profissionais da Educação Básica, com a finalidade de fixar seus princípios e objetivos, e de organizar seus programas e ações, em regime de colaboração entre os sistemas de ensino e em consonância com o PNE.

No Art. $2^{\circ}$ do Decreto $n^{\circ} 8.752 / 16$ dispõe que para atender às especificidades do exercício de suas atividades e aos objetivos das diferentes etapas e modalidades da educação básica, a formação dos profissionais da educação terá como princípios:

I - o compromisso com um projeto social, político e ético que contribua para a consolidação de uma nação soberana, democrática, justa, inclusiva e que promova a emancipação dos indivíduos e dos grupos sociais;

II - o compromisso dos profissionais e das instituições com o aprendizado dos estudantes na idade certa, como forma de redução das desigualdades educacionais e sociais;

III - a colaboração constante, articulada entre o Ministério da Educação, os sistemas e as redes de ensino, as instituições educativas e as instituições formadoras;

IV - a garantia de padrão de qualidade nos cursos de formação inicial e continuada;

V - a articulação entre teoria e prática no processo de formação, fundada no domínio de conhecimentos científicos, pedagógicos e técnicos específicos, segundo a natureza da função;

VI - a articulação entre formação inicial e formação continuada, e entre os níveis, as etapas e as modalidades de ensino;

VII - a formação inicial e continuada, entendidas como componentes essenciais à profissionalização, integrando-se ao cotidiano da instituição educativa e considerando os diferentes saberes e a experiência profissionais [...]. (BRASIL, 2016, p. 2).

No contexto da educação nacional, a concepção de formação continuada apresentada pelos Referenciais para a Formação de professores (BRASIL, 1999) diz o seguinte:

[...] aqui a formação é entendida como um processo contínuo e permanente de desenvolvimento, o que pede do professor disponibilidade para a aprendizagem; da formação, que o ensine a aprender; e do sistema escolar no qual ele se insere como profissional, condições para continuar aprendendo. Ser profissional implica ser capaz de aprender sempre. (BRASIL, 1999, p. 63).

Esse documento reconhece o quadro de insuficiência e debilidades no que se refere aos setores político-administrativo, organizacional e metodológico da formação continuada:

[...] falta de articulação entre várias instâncias de gestão do sistema, a descontinuidade dos projetos e programas de um governo para outro, a pressa com que as ações são planejadas e realizadas para atender às limitações do 
tempo político das administrações, a falta de incentivos salariais ou institucionais para que os professores participem de programas de formação e a inexistência de tempo previsto na jornada de trabalho e no calendário escolar para formação em serviço [...]. [...] não se planeja de forma articulada ações extensivas e de profundidade, priorizando-se a alternativa de grandes eventos pontuais cujo efeito é bastante relativo e discutível [...] não há como considerar suas reais necessidades e avanços em atividades desse tipo (BRASIL, 1999, p. 66).

A importância de adequação das propostas de ações de formação às necessidades impostas se faz necessária à resolução de problemas e dificuldades no campo da formação continuada e à superação de modelos e práticas ineficazes, pois há urgência de adequações qualitativas, na medida em que:

[...] a inexistência de mecanismos de acompanhamento contínuo da prática pedagógica, de avaliação periódica dos resultados das ações desenvolvidas e de identificação de demandas de formação, colocadas pelas dificuldades que encontram os professores no exercício profissional, que prejudica a qualidade de formação, uma vez que estes são instrumentos de avaliação fundamentais para o planejamento e redimensionamento dos programas (BRASIL, 1999, p. 47).

Com base nestas informações, podemos afirmar que a formação continuada de professores vem sendo considerada, do ponto de vista oficial, como um mecanismo importante para a qualificação do ensino, este fato pode ter sido um dos fatores motivadores do crescente número de ações, visando à formação continuada de professores.

\section{A formação continuada: os saberes e a prática reflexiva dos professores}

Segundo Pérez Gómez (2001), a preocupação pelo desenvolvimento profissional do professor na formação e na prática educativa se converteu em objeto de estudos teóricos que apontam a necessidade de se enriquecer o desenvolvimento profissional docente para se incrementar a qualidade do ensino e transformar a escola. Para esse autor, a busca da identidade do professor e de sua autonomia profissional supõe respeitar a diversidade dos saberes docentes e as diferenças de concepções teóricas e práticas profissionais.

Pimenta (2000) trata da questão da identidade como algo pertencente à formação do professor, seja ela inicial ou continuada. Para essa autora a identidade do professor é um processo de construção que reflete o contexto e momento históricos, respondendo, dessa forma, às novas demandas colocadas pela sociedade.

A autora Pimenta (1999) ressalta a necessidade da mobilização dos saberes da experiência para a construção da identidade profissional do professor. Neste sentido, são 
identificados três tipos de saberes da docência: a) da experiência, que seria aquele aprendido pelo professor desde quando aluno, com os professores significativos etc., assim como o que é produzido na prática num processo de reflexão e troca com os colegas; b) do conhecimento, que abrange a revisão da função da escola na transmissão dos conhecimentos e as suas especialidades num contexto contemporâneo e c) dos saberes pedagógicos, aquele que abrange a questão do conhecimento juntamente com o saber da experiência e dos conteúdos específicos e que será construído a partir das necessidades pedagógicas reais (PIMENTA, 1999, p. 20-22).

Tardif (2002) enfatiza sobre saberes e formação docente no sentido que deve haver nova articulação e novo equilíbrio entre os conhecimentos produzidos nos cursos de formação de professores e os saberes desenvolvidos pelos professores em suas práticas:

[...] nossa proposta de trabalho constitui um discurso em favor de uma racionalidade limitada e concreta, enraizada nas práticas cotidianas dos atores, racionalidade aberta, contingente, instável, alimentada por saberes lacunares, humanos, baseados na vivência, na experiência, na vida. (TARDIF, 2002, p. 224).

Concordamos com Mizukami (1996) quando afirma que o processo de aprender a ensinar, ou seja, de aprender a ser professor, é processo de longa duração, que somente tem início, sem final pré-estabelecido. Nas situações complexas de sala de aula é que ocorre, em grande parte, essa aprendizagem, muitas vezes, com poucas oportunidades desse profissional refletir sobre a prática, a fim de que possa analisá-la e interpretá-la, tendo que agir de forma intuitiva na resolução dos problemas que se apresentam nesse contexto.

Vemos que o ser/estar professor é um processo em construção, ao longo de toda sua história, que é adquirido, conforme Tardif (2002, p. 14), "no contexto de uma socialização profissional, onde é incorporado, modificado, adaptado em função dos momentos e das fases de uma carreira".

Podemos considerar que a perspectiva de formação continuada de professores existe sob distintas denominações e com algumas particularidades, apresentam-se modelos de formação continuada em que o professor deixa de ser um técnico, um executor, para transformar-se em um investigador em sala de aula, um professor reflexivo, que entenda as relações intrínsecas ao contexto e às condições de seu trabalho.

Segundo Zeichner (1995) o professor reflexivo é aquele que assume atitude reflexiva em relação ao seu ensino e às condições sociais que o influenciam, o autor nos adverte que há variações na forma como se consideram o processo de reflexão, no conteúdo da reflexão, na condição prévia à reflexão e no produto da reflexão, sendo que a ação reflexiva segundo o autor

[...] é um processo que implica mais do que a busca de soluções lógicas e racionais para os problemas. A reflexão implica intuição, emoção e paixão; 
não é portanto, nenhum conjunto de técnicas que possa ser empacotado e ensinado aos professores. (ZEICHNER, 1995, p. 121).

Para delimitar o que exatamente se entende por professor reflexivo, reportamos a Pimenta (1997) que expressa seu entendimento a respeito da questão, opondo-se à racionalidade técnica que marcou o trabalho e a formação de professores, entende-o como um intelectual em processo contínuo de formação. Enquanto tal, pensar sua formação significa pensá-la como uma continuação de formação inicial,

[...] a formação é, na verdade, autoformação, uma vez que os professores reelaboram saberes iniciais em confronto com suas experiências e práticas, cotidianamente vivenciadas nos contextos escolares. É nesse confronto e num processo de troca de experiências e práticas que os professores vão constituindo seus saberes como uma prática, ou seja, aquele que constantemente reflete na e sobre a prática. (PIMENTA, 1997, p. 56).

Entendemos que o desenvolvimento da capacidade reflexiva do professor lhe propicia condições de assimilar melhor as mudanças que causam impacto na escola. Podemos dizer ainda que, o professor reflexivo tem condições de repensar e avaliar constantemente sua prática pedagógica.

Schön (1995) centralizou sua concepção de desenvolvimento de uma prática reflexiva em três ideias centrais: conhecimento na ação (intuitivo, espontâneo, experimental); reflexão na ação (produção de uma pausa - para refletir - em meio à ação presente) e reflexão sobre a reflexão na ação (reflexão sobre a reflexão da ação passada e que influi diretamente em ações futuras, colocando à prova uma nova compreensão do problema). Propôs uma epistemologia assentada na reflexão na ação, defendendo que, ao refletir na ação, o profissional pode encontrar soluções para o problema que se apresenta no contexto do cotidiano.

Pimenta e Ghedin (2002) constroem uma crítica ao conceito de "professor reflexivo", sugerem que o ensino como prática reflexiva tem um aspecto positivo, apontando para a valorização da produção de saber docente a partir da prática, colocando em destaque o protagonismo do professor. Porém, nos processos de mudança e inovações, pode-se gerar a supervalorização do professor como indivíduo, perdendo de vista o contexto social mais amplo e o trabalho coletivo.

Candau (1996) ao estudar a formação continuada de professores revela tendências, destacando três eixos como pontos centrais de referências para se repensar a formação continuada de professores. São eles: (a) a escola deve ser vista como lócus de formação continuada; (b) todo o processo de formação continuada deve ter como referência os saberes dos professores; (c) a consideração das diferentes etapas de desenvolvimento do professor. 
O primeiro eixo é o que tem por base tomar a escola como lócus de formação, ou seja, compreende-se que "[...] o dia-a-dia na escola é um locus de formação" (CANDAU, 1996, p. 144), a fim de que o cotidiano escolar se torne um espaço significativo de formação é importante que a prática pedagógica seja reflexiva no sentido de identificar problemas e resolvê-los e acima de tudo, seja uma prática coletiva, construída por grupos de professores ou por todo corpo docente de determinada escola.

Nesse contexto Nóvoa (1995, p. 20) atribui às escolas um espaço privilegiado para a aquisição de conhecimentos, onde os professores são preparados para a difusão dos conhecimentos historicamente construídos, como também "um lugar de reflexão sobre as práticas, o que permite vislumbrar uma perspectiva dos professores como profissionais produtores de saber e de saber fazer".

Alguns estudos foram desenvolvidos já considerando a escola como importante espaço da formação continuada, de acordo com Candau (1996):

O locus da formação a ser privilegiado é a própria escola; é preciso deslocar o locus da formação continuada de professores da universidade para a própria escola [...]. Considerar a escola como locus de formação continuada passa a ser uma afirmação fundamental na busca de superar o modelo clássico de formação continuada e construir uma nova perspectiva na área de formação continuada de professores. (CANDAU, 1996, p.144).

Nóvoa (1992) também ressalta esta importância da escola para o desenvolvimento profissional dos professores, numa perspectiva de mudança tanto dos professores como da escola, considerando seus espaços coletivos como um excelente instrumento de formação, contemplando não somente a atualização inerente ao progresso dos conhecimentos científicos, mas também as experiências profissionais valorizadas, a partir de uma reflexão formativa e investigação nos contextos de trabalho.

O segundo eixo abordado por Candau (1996) diz respeito à valorização do saber docente, também fundamentado em Tardif (2002), que classifica os saberes docentes em plural, pois são constituídos por vários saberes (das disciplinas, dos saberes profissionais e dos saberes da experiência); o autor acredita que os professores ocupam uma posição significativa no interior das complexas relações entre sociedade e os saberes por ela produzidos e mobilizados com diversos fins e desvalorizado, porque 48 mesmo os professores ocupando posição estratégica em relação aos saberes produzidos socialmente, eles devem ser valorizados pelos saberes que possuem e transmitem.

O terceiro eixo orientador das atuais tendências da formação continuada de professores, segundo Candau (1996), centra-se na consideração do ciclo de vida dos docentes, que de acordo 
com o estudo de Huberman (1992), o professor passa por uma fase de sobrevivência e descoberta, ao iniciar seu percurso profissional, que possibilita o confronto com o novo e a exploração de possibilidades de ação, avançando, gradativamente, para uma fase de estabilização, em que começa a tomar uma maior consciência do seu papel e responsabilidade enquanto educador.

A seguir o relato de Gemente e Matthiesen (2017), sobre a experiência de uma ação de formação continuada realizada com a participação de 21 professores de Educação Física da rede municipal de Educação de Goiânia:

Com a possibilidade de colocar em prática os estudos e as vivências realizados durante o curso de formação continuada, os professores puderam avaliar, refletir e dialogar sobre as suas práticas e contribuições do curso. Diferente das dificuldades, das limitações e dos receios em trabalhar com todas as provas do atletismo que foram apresentados pelos professores no início da pesquisa, foi possível verificar diversas contribuições do processo desenvolvido, tais como: a construção de novos conhecimentos que contribuíram para superar lacunas deixadas na formação inicial, o que possibilitou trabalhar com as provas do atletismo, em todos os ciclos de aprendizagem, que nunca haviam sido trabalhados; as vivências e as discussões realizadas estimularam a criatividade para o desenvolvimento de novas práticas e proporcionaram a elevação da autoestima dos professores. (GEMENTE; MATTHIESEN, 2017, p. 195).

Diante dessas considerações, a formação continuada de professores deve ser concebida como um dos componentes de transformação da escola e estar articulada com a gestão escolar, práticas curriculares e as necessidades identificadas dos professores. É, portanto, no processo construído cotidianamente a partir de uma prática pedagógica crítico-reflexiva, que podemos pensar a formação continuada do professor contextualizada histórica e socialmente e, consequentemente, o processo de ensino-aprendizagem com vistas à qualidade do trabalho docente e da educação.

\section{Considerações finais}

No Brasil, a formação continuada de professores possui uma trajetória histórica que é marcada por diferentes tendências que surgiram diante da realidade brasileira.

Destacamos que existem os avanços nas legislações sobre a formação continuada de professores, e que os municípios juntamente com a União têm a responsabilidade em ofertar a formação continuada. Importante mencionar que, entre as metas e estratégias do PNE para o decênio iniciado em 2014 está a qualidade da formação e capacitação de professores para a educação básica. 
Ressaltamos a importância dos professores em refletir criticamente sobre sua prática cotidiana para compreender tanto as características do processo de ensino-aprendizagem quanto do contexto em que o ensino ocorre, de modo que no momento da formação continuada possa permitir a conquista de complementar, mudar e melhorar a formação já obtida, isto é, de oportunizar aos professores superar os desafios rumo à formação de alunos cada vez mais críticos, capazes, autônomos, solidários, democráticos e cidadãos.

É importante que a formação continuada promova um espaço de escuta e de diálogo com os professores, no sentido de aproximar as ações formativas das suas necessidades, inserir a formação no contexto de sala de aula, usando os problemas advindos dessa instância como eixo norteador para os demais temas, assim contribuirá mais para tornar as ações formativas mais significativas para os docentes.

Percebemos a importância da formação continuada para a construção de novos conhecimentos e da necessidade de elaboração de novas práticas que sejam significativas para a aprendizagem dos alunos. Os saberes dos professores têm relação com a ação pedagógica ocorrida no percurso da vida escolar, passando pelas vivências fora da escola e no trabalho docente de sala de aula, num processo permanente de reflexão sobre a prática.

\section{REFERÊNCIAS}

ALARCÃO, I. Formação continuada como instrumento de profissionalização docente. In: VEIGA, I. P. A. (Org.) Caminhos da profissionalização do magistério. Campinas, SP: Papirus, 1998.

AMORIM, R. M. de A.; MAGALHAES, L. K. C. de. Formação continuada e práticas formadoras.Cad. CEDES, Campinas, v. 35, n. 95, p. 9-12, Abr. 2015. Disponível em: <http://www.scielo.br/scielo.php?script=sci_arttext\&pid=S0101-32622015000100009>. Acesso em:12 jan. 2018.

AZEVEDO, L. C. S. S.; MAGALHÃES, L. K. C. de. Formação Continuada e suas implicações: entre a lei e o trabalho docente. Cad. Cedes, Campinas, v. 35, n. 95, p. 15-36, jan.-abr., 2015. Disponível em: <http://www.scielo.br/pdf/ccedes/v35n95/0101-3262-ccedes35-95-00015.pdf>. Acesso em 27 fev. 2018.

BRASIL. Decreto $n^{\circ} 8.752$, de 9 de maio de 2016. Dispõe sobre a Política Nacional de Formação dos Profissionais da Educação Básica. Diário Oficial da União, Brasília/DF, 2016.

BRASIL. Lei 9.394, de 1996. Regulamenta as Diretrizes e Bases da Educação Nacional. Diário Oficial [da] República Federativa do Brasil, Brasília, 1996.

BRASIL. Lei n ${ }^{\circ} 13.005$, de 25 de junho de 2014. Aprova o Plano Nacional de Educação PNE e dá outras providências. Diário Oficial da União, Brasília, 26 jun. 2014.

BRASIL. Referenciais para Formação de Professores. Brasília: Ministério de Educação e Cultura. Secretaria de Educação Fundamental, 1999. 
BRASIL. Resolução $n^{\circ} 2$, de $1^{\circ}$ de julho de 2015. Define as Diretrizes Curriculares Nacionais para a formação inicial em nível superior e para a formação continuada. Diário Oficial da União, Brasília, 2015. Disponível em: < http://portal.mec.gov.br/index.php?option=com_docman\&view=download\&alias=17719rescne-cp-002-03072015\&category_slug=julho-2015-pdf\&Itemid=30192>. Acesso em: 25 jan. 2018.

CANDAU, V. M. F. Formação Continuada de professores: tendências atuais. In: REALI, A. M. de M. R.; MIZUKAMI, M. da G. N. (Orgs.). Formação de professores: tendências atuais. São Carlos: EDUFSCar, 1996. p.139-152.

GATTI, B. A. Análise da política públicas para formação continuada no Brasil, na última década. Revista Brasileira de Educação, Rio de Janeiro, Anped; v. 13, n. 37, p. 57-70, jan./abr. 2008.

GEMENTE, F. R. F.; MATTHIESEN, S. Q. Formação continuada de professores: construindo possibilidades para o ensino do atletismo na Educação Física escolar. Educ. rev., Curitiba, n. 65, p. 183-200, set. 2017. Disponível em:

$<$ http://www.scielo.br/scielo.php?script=sci_arttext\&pid=S010440602017000300183\&lng=en \&nrm=iso>. Acesso em: 13 fev. 2018.

HUBERMAN, M. O Ciclo de vida profissional dos professores. In: NÓVOA, A. (org.). Vidas de professores. 2. ed. Portugal: Porto Editora, 1992. p. 31-61.

LIMA, M. S. L. A formação contínua do professor nos caminhos e descaminhos do desenvolvimento profissional. 2001. 188 f. Tese. (Doutorado em Educação) São Paulo: Faculdade de Educação/USP, 2001.

MIZUKAMI, M. da G. N. Docência, Trajetórias Pessoais e Desenvolvimento Profissional. In: REALI, A.M.M.R.; MIZUKAMI, M.G.N. (Orgs.) Formação de professores: Tendências Atuais. São Carlos: EDUFSCAR, 1996, p.59-91.

NÓVOA, A. (Org.). Vidas de professores. Porto: Porto Editora, 1992.

NÓVOA, A. Formação de professores e profissão docente. In: NÓVOA, A. (Coord.). Os professores e sua formação. 2. ed. Lisboa: Dom Quixote, 1995, p. 15-43.

PÉREZ GÓMEZ, A. I. A Cultura Escolar na sociedade neoliberal. Tradução Ermani Rosa. Porto Alegre: Artmed Editora, 2001.

PIMENTA, S. G. Didática como mediação na construção da identidade do professor - uma experiência de ensino e pesquisa na licenciatura. In: ANDRÉ, M. E. D. A; OLIVEIRA, M. R. N. S. (Orgs.). Alternativas do ensino de didática. Campinas: Papirus, 1997.

PIMENTA, S. G. Formação de professores: identidade e saberes da docência. In: PIMENTA, S. G. (Org). Saberes pedagógicos e atividade docente. São Paulo: Cortez Editora, 1999.

PIMENTA, S. G. Professor reflexivo: construindo uma crítica. In: PIMENTA, S. G. (Org). Saberes pedagógicos e atividade docente. São Paulo: Cortez, 2000.

PIMENTA, S. G.; GHEDIN, E. (Orgs). Professor reflexivo no Brasil: gênese e crítica de um conceito. São Paulo: Cortez, 2002.

SCHÖN, D. A. Formar professores como profissionais reflexivos. In: NÓVOA, A. (Coord.). Os professores e a sua formação. Lisboa: Dom Quixote, 1995, p. 77-91.

TARDIF, M. Saberes docentes e formação profissional. 2 ed. Petrópolis: Vozes, 2002. 
ZEICHNER, K. M. Novos caminhos para o praticum: uma perspectiva para os anos 90. In: NÓVOA, A. (Org.). Os professores e a sua formação. Publicações Dom Quixote, Lisboa, 1995. p. 115-134.

Artigo recebido em: 16/03/2018

Artigo aceito em: 16/05/2018 